\title{
Analogías y continuidades en el Concierto para violonchelo $y$ orquesta de Ligeti
}

\author{
Mariano Etkin, María Cecilia Villanueva* \\ Universidad Nacional de La Plata
}

\section{Resumen:}

Se analiza el carácter atípico de la obra, que no es un concierto decimonónico convencional, centrándose casi excluyentemente en el Primer Movimiento. Se estudian los procedimientos constructivos en base al "cluster" y las texturas derivadas. El repertorio armónico restringido y las austeras apariciones melódicas favorecem la organización de continuidades tímbricas y de analogias formales en la macroforma. La contigüidad, característica esencial del cluster, y el tratamiento indiferenciado entre el solista y la orquesta funcionan como garantes de la continuidad.

Palabras clabe: análisis musical; música del siglo XX; cluster; textura; continuidad

* Mariano Etkin y María Cecilia Villanueva se desempeñan como Profesor Titular y Profesora Adjunta en la cátedra de Composición de la Facultad de Bellas Artes. Universidad Nacional de La Plata, Argentina. Son directores del proyecto de investigación Músicas del siglo XX: materiales y procedimientos de la composición, en la misma universidad. 


\section{"Du siehst, mein Sohn, zum Raum wird hier die Zeit".}

"Die Zeit steht still - wie der Raum[...]"2

En la segunda mitad del siglo XX el conflicto entre una música de raíz contrapuntística y dinámica, lineal u horizontal en su concepción primera, y una música vertical, estática, imaginada a partir de bloques o conglomerados de alturas, es posible que haya sido uno de los más ricos en consecuencias. El conflicto se remonta a finales del siglo XIX, con la disgregación de las funciones armónicas tonales y de las formas vinculadas a ellas. En ese momento, dentro del abanico de innovaciones y rupturas, los aportes de Satie y Debussy fueron decisivos en cuanto a la textura, el timbre y la forma. Paralelamente, la aparición de un tiempo musical quieto, "liso", desentendido del desarrollo temático convencional y manipulado como si fuese un espacio atemporal sujeto a operaciones diversas, instala una manera diferente de imaginar la música. El tiempo "liso" se muestra embrionariamente en ciertas obras de compositores como Schubert, Chopin o Berlioz, bajo la forma de breves momentos de discontinuidad con respecto al devenir sonoro: ${ }^{3}$ zonas de transición de longitud desusada ${ }^{4}$ en las que llega a detenerse el flujo enunciativo, o movimientos enteros en los que el predominio de la repetición termina anulando todo contraste dinamizador. ${ }^{5}$

\footnotetext{
1. Richard Wagner, Parsifal. Gurnemanz a Parsifal (1er. Acto). "Ves, hijo mío, aquí el tiempo será espacio".

${ }^{2}$ György Ligeti, 'El tiempo permanece inmóvil, como el espacio [...]".Trad. María Cecilia Villanueva y Mariano Etkin. Ich will eine schmutzige Musik, eine irisierende Musik... Entrevista de Marina Lobanova. Neue Zeitschrift für Musik (NMZ), n. 3, p. 17, mayo-junio 2003. [(Quiero una música "súcia", una música iridiscente...). Arte y Opinión, n. 2, p. 29. 2006].

${ }^{3}$ Uno de esos momentos, en la música de Schubert, es analizado con lucidez en Schnebel, Dieter: Composition 1960: La Monte Young (1971). Musique en jeu, n. 11, jun. 1973.

${ }^{4}$ Ver, por ejemplo, la Polonesa op. 44 n. 5, en Fa\# menor de Chopin. cc. 83-102; o la Cuarta Sinfonía de Brahms, 1er. movimiento, compases 227-258.

${ }^{5}$ La Marche des Pélerins de Haroldo en Italia, de Hector Berlioz, es un buen ejemplo, sin olvidar los numerosos momentos que ofrece la música de Mahler, entre ellos el final de Das Lied von der Erde.
} 
El tiempo "liso" ocupa un lugar fundamental en la música estadounidense. Más evidente en Cowell que en Ives y ampliamente utilizado por Cage, Feldman y La Monte Young, su irrupción intensiva en la música europea se produce a través de lannis Xenakis y György Ligeti, dos compositores marginales en más de un sentido. Xenakis y Ligeti proponen una música imaginada a partir del timbre, las bandas de registro, los modos de ataque y las densidades como organizadores básicos de la composición, continuando algunas de las ideas de Edgard Varese. En 1955 Xenakis escribe un texto cuyo título es un manifiesto: “La crisis de la música serial" (1955). En ese ensayo se cuestionan los axiomas seriales que habían convertido a la obra en un vehículo de procedimientos constructivos, desentendiéndose de obvios resultados perceptivos. Poniendo el máximo énfasis en el eje melódico-lineal, el serialismo de los años cincuenta dejó que el plano vertical no resultara más que una consecuencia de aquél: el control extremo de las alturas horizontales coexistía con una implícita despreocupación por las resultantes verticales y oblicuas. Por el contrario, las "nubes" de Xenakis - en sus obras Metastaseis (1953-54) y Pithoprakta (1955-56) - las posteriores bandas registrales de Ligeti, elaboradas micro-polifónicamente, constituyen claras muestras de un pensamiento en el que la altura individual ha dejado de ser la variable prioritaria. El cluster - uno de los materiales centrales de la música moderna, introducido por Henry Cowell y Charles Ives a principios del siglo XXes el fundamento armónico de esas "nubes" y bandas registrales. La conjunción del cluster con la duración extendida y una pulsación metronómica baja confluyen para la materialización del tiempo "liso"; éste no solo define un coeficiente nulo o muy bajo de actividad sino que interviene decisivamente en la conformación de la textura. Es en ella, sobre todo, donde pueden verse con claridad los atributos de aquella manera diferente de imaginar la música. A partir de las obras de Xenakis ya citadas y de Apparitions (1958-59) y Atmosphères (1961) de Ligeti, la música europea incorpora texturas que despliegan, de manera organizada y consecuente, esas zonas de tiempo "liso". Cuando esas zonas se vuelven prioritarias en la definición de las características esenciales de la obra, se produce un punto de inflexión en la historia de la música. Desde luego, se puede 
trazar una genealogía de la que participa decididamente la clásica Pieza n. 3 del op.16 (Farben) de Schönberg, de 1909. El lugar predominante que comienzan a ocupar texturas y timbres en el armazón constructivo, no necesariamente conduce a una negación de los binomios habituales como tensión/distensión, similitud/contraste, ruido/sonido. El tiempo "liso", por otro lado, favorece una concentración del foco auditivo en los más mínimos detalles tímbricos $y$, simultáneamente, en las grandes articulaciones de la textura. Aquellos fragmentos aislados - detenciones y estatismos más o menos imprevistos que aparecían en los compositores del siglo XIX ya mencionados - en Ligeti se expanden y abarcan la totalidad de la obra. El momento excepcional, transitorio, se vuelve norma: la transgresión se instala y desplaza al sistema transgredido. ${ }^{6}$

En Apparitions el timbre y la textura se presentan cual verdadero cuerpo recuperado de la música, el mismo que Varese había retomado de Berlioz. Además la música de Ligeti incluye sensaciones táctiles y ópticas transfiguradas en timbres y texturas pero al margen de cualquier propósito ilustrativo o literario. ${ }^{7}$ Esta reaparición de la materia sonora no debe entenderse como el retorno de una intención crudamente hedonista ni como vector de un deseo de "comprensibilidad" de espúreo acercamiento al oyente, sino como reintroducción del "grano" del que habla Roland Barthes (1986).

El Concierto para violonchelo y orquesta de György Ligeti, compuesto en 1966, está dividido en dos Movimientos. La orquesta tiene dimensiones reducidas: vientos a uno, no hay percusión y las cuerdas están representadas por un grupo que, según las opciones que da el compositor, puede variar entre una mínima expresión (quinteto) y una orquesta de cuerdas mediana. La relación

\footnotetext{
${ }^{6}$ Como modelo de este movimiento habitual en la cultura occidental puede mencionarse lo ocurrido con la disonancia en el contexto de la armonía tonal y su evolución en el siglo XX.

7 “[...] musique à programme sans programme, une musique fortement pénétré par des associations, mais de la musique pure". (Música programática sin programa, música repleta de asociaciones pero música pura). (Häusler, 1974, p. 119).
} 
entre el solista y la orquesta no es la tradicional del concierto en su versión decimonónica; la oposición solo-tutti se diluye en una integración en la que el solista nunca adquiere un rol protagónico excluyente. Esta relación imprecisa en cuanto a las jerarquías de los instrumentos participantes y la ausencia de cualquier virtuosismo exhibicionista por parte del solista están claramente expuestas en el Primer Movimiento. En el Segundo Movimiento los pasajes virtuosísticos del solista son breves, de carácter más bien paródico y están enmarcados por comportamientos de un virtuosismo similar en el tuttiorquestal.

La complementación entre solista y orquesta se muestra por medio de una textura diferente en cada uno de los movimientos. En el Primero se observa un tratamiento "liso" del tiempo por el predominio de notas largas y baja densidad cronométrica; en el Segundo, por el contrario, se utiliza una partición "estriada" del continuo temporal y una mayor actividad instrumental en ambas fuentes sonoras. En ninguno de los dos Movimientos hay silencios absolutos, a excepción de los finales, en los que la música se disuelve en la nada; cada extinción tiene un carácter diferente. En el Primer Movimiento, además, la extinción se da por partida doble: el solista se detiene ante la imposibilidad técnica de seguir ascendiendo en el registro - Ligeti indica morendo, "sofocado" y la orquesta se reduce a una expresión mínima, quedando solamente el contrabajo en el registro grave, con la indicación diminuendo, morendo al niente. ${ }^{8}$ Por otro lado, simétricamente, ambos movimientos terminan con un instrumento solo: en el Primero lo hace el contrabajo, que no es el solista; el Segundo lo cierra el solista, por medio de una cadencia desplazada de su lugar habitual. Se trata de una cadencia en su doble acepción. Es un pasaje virtuosístico de carácter tal vez paródico y también es el momento final, "caída" o cierre de la obra. En esta cadencia hay un predominio del ruido cada vez mayor hasta volverse excluyente, para terminar disgregándose también poco a poco, morendo al niente como ocurría en el Primer Movimiento. La oposición textural entre los dos Movimientos tiene otros correlatos simétricos, teniendo en cuenta la totalidad de la

${ }^{8}$ El morendo al niente se despliega también en la disminución gradual de la cantidad de alturas utilizadas (3-2-1) a partir del compás 63 del Primer Movimiento. 
obra, que se inicia con el solista sin ningún acompañamiento y con una sola altura definida; la misma textura - solista tocando solo - cierra la obra pero desarrollándose únicamente sobre el ruido, en clara vinculación simétrica por oposición. Otra relación simétrica por oposición se observa entre el comienzo del Primer Movimiento, a cargo del solista y el comienzo del Segundo, a cargo de la orquesta.

A continuación nos ocuparemos en detalle del Primer Movimiento.

El Primer Movimiento, que abarca 77 compases, se divide en dos secciones; los cambios tímbrico-texturales señalan esa división. Ambas secciones se dividen en dos partes casi simétricas (Tabla 1).

Tabla 1 División formal del Primer Movimiento

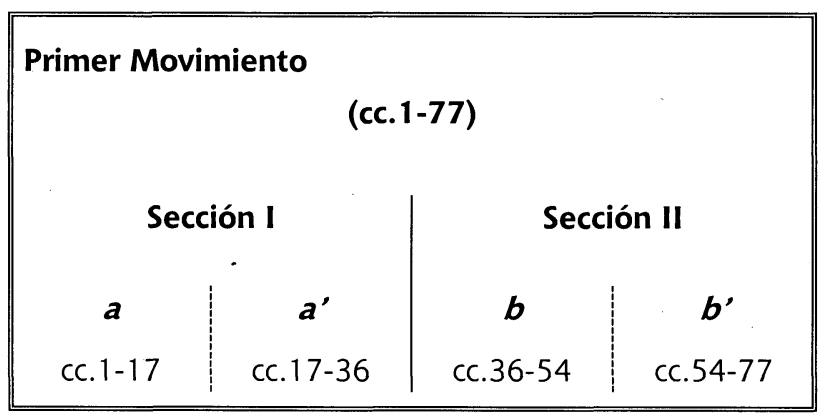

El material básico sobre el que está construido este Movimiento es un cluster cromático al que se llega de manera gradual, partiendo de una sola altura ejecutada por el solista. El proceso de expansión del cluster, en el que participan el solista y la orquesta hasta cubrir un ámbito de 5ta. justa, ocupa la Sécción I. Es importante señalar que se llega a la máxima expansión en el compás 28 con la entrada de la altura más aguda del cluster, cuyo ámbito (Re-La) está delimitado por el solista, en el único momento en que aparece una doble cuerda en todo el Movimiento, por medio de un doble armónico natural (Figura 1). 


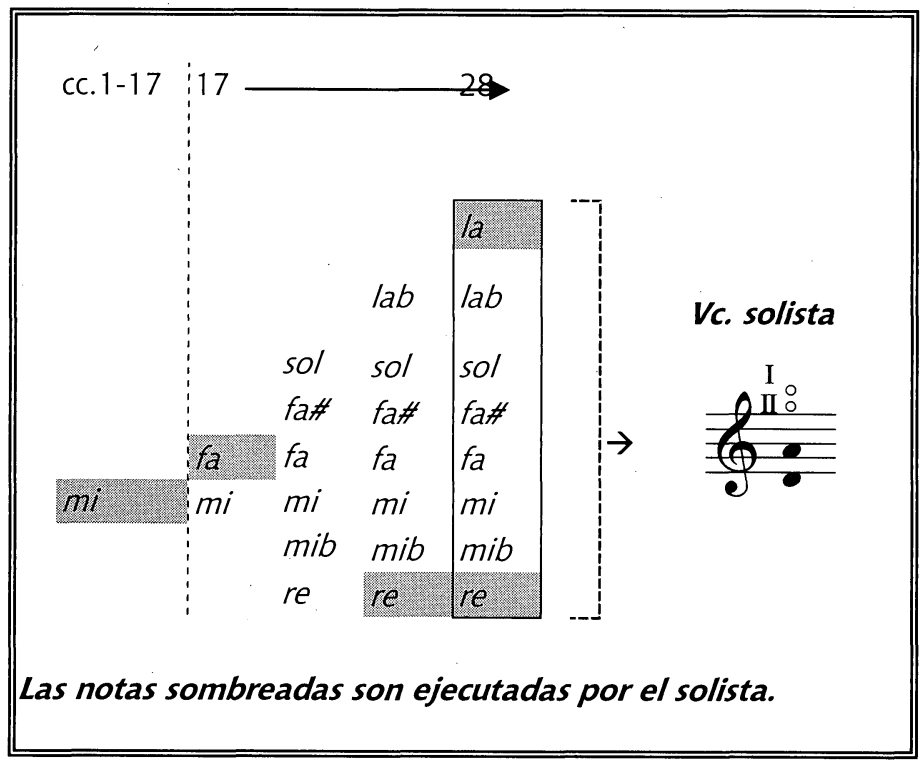

Figura 1 Formación del cluster en la Sección I

Los primeros 17 compases (a) de la Sección I transcurren sobre una sola altura (Mi). En los restantes compases ( $\left.\boldsymbol{a}^{\prime}\right)$ se agregan paulatinamente las demás alturas hasta completar el cluster.

El punto de máxima expansión (c. 28) coincide con una permutación tímbrica en el grupo de cuerdas (Tabla 2).

Tabla 2 Permutación tímbrica del cluster

\begin{tabular}{|c|c|c|c|c|}
\hline \multicolumn{3}{|c|}{ c. 26} & \multicolumn{2}{|c|}{ c. 28} \\
\hline & & & $\begin{array}{l}\text { Vc. solista } \\
\text { (Fl. + Ob.) }\end{array}$ & $\begin{array}{l}l a \\
l a b\end{array}$ \\
\hline sol & VI. I & $\rightarrow$ & Va. & sol \\
\hline faAt & Vc. & $\rightarrow$ & $\mathrm{Cb}$. & fatt \\
\hline fa & $\mathrm{Cb}$. & $\rightarrow$ & VI. II & fa \\
\hline$m i$ & Va. & $\rightarrow$ & Vc. & $m i$ \\
\hline mib & VI. II & $\rightarrow$ & VI. I & mib \\
\hline re & Vc. solista & $\Leftrightarrow$ & Vc. solista & re \\
\hline
\end{tabular}


Como se observa en la Tabla 2, el Re es la única nota que no cambia de instrumento, aunque sí de timbre, ya que se transforma de nota pisada (c. 26) en armónico natural (c. 28); por otro lado, el Mib no cambia de timbre pero sí de instrumento, pasando del Violín II al Violín I. Estos cambios sutiles son una buena muestra del trabajo en torno a la mínima variación.

El cluster cromático se mantiene hasta el compás 34. Desde ahí hasta el compás 36 se producen vacíos por supresión alternada de sonidos del cluster, con excepción del sonido más agudo (Tabla 3 ).

Tabla 3 Esquema de supresión de notas del cluster en la Sección I

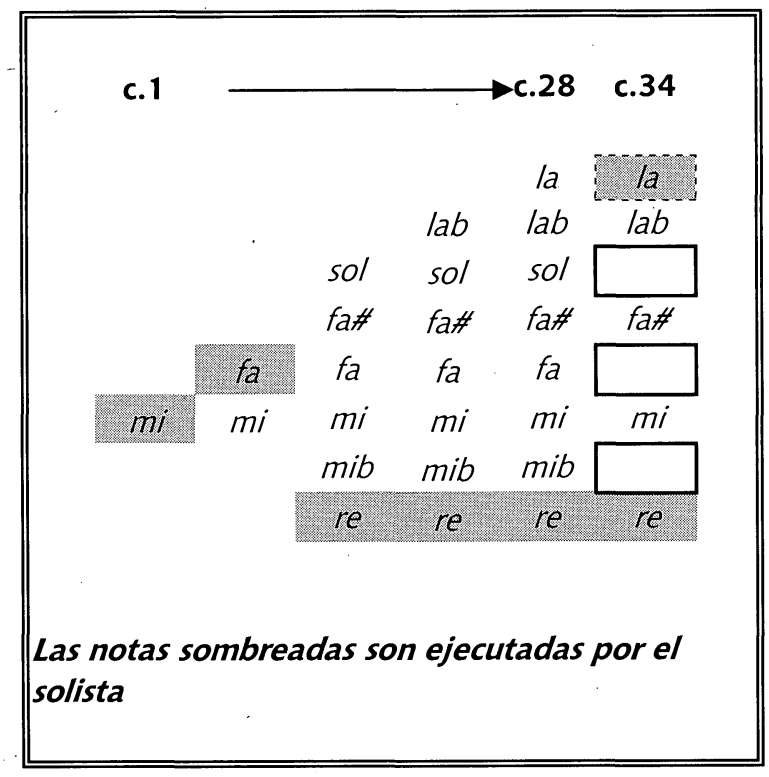

La excepción que constituye la permanencia del sonido más agudo (La), a cargo del solista, en el esquema mencionado de supresiones (ver Tabla 3), se explica como garantía para la continuidad cromática en la siguiente sección, que se inicia con el Sib del compás 36 (Figura 2). 


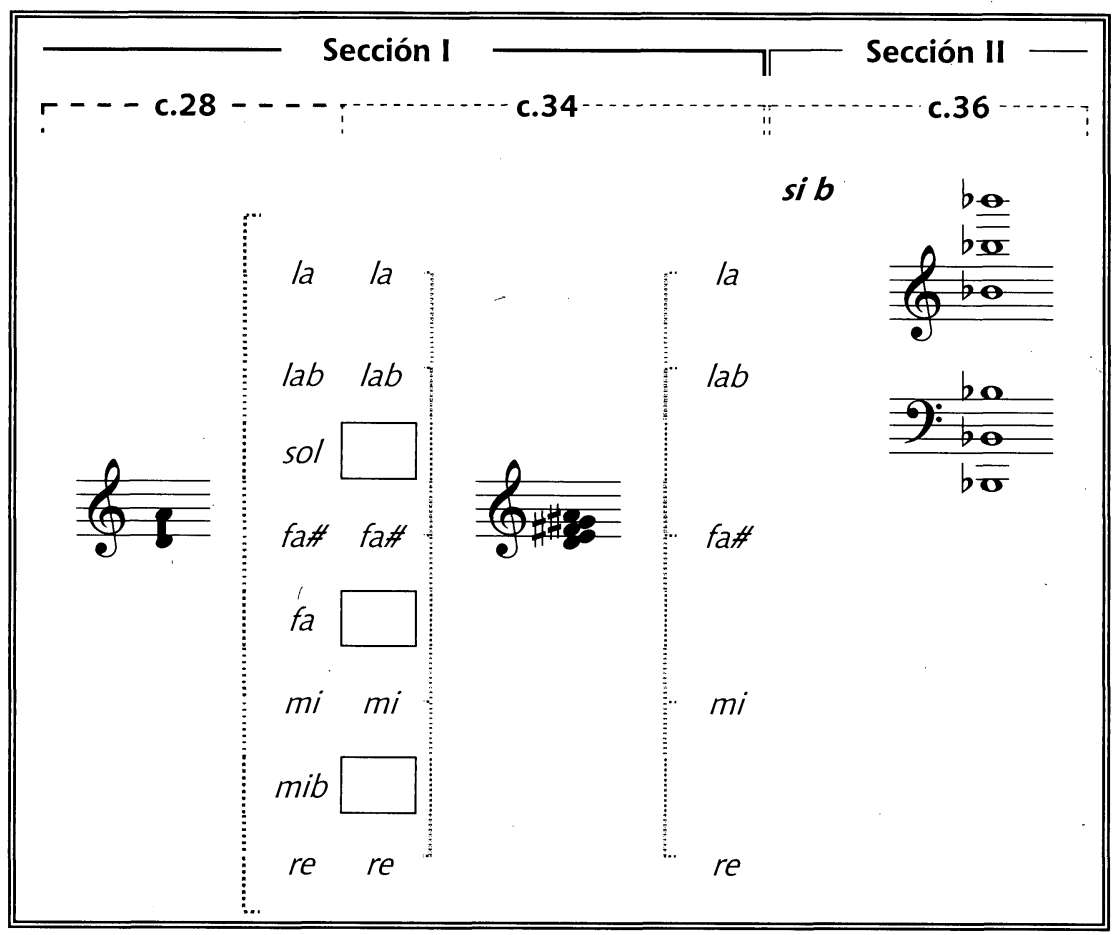

Figura 2 Proceso de desintegración del clustery continuidad cromática entre las Secciones I y II

En la segunda mitad del compás 36 aparece un nuevo sonido (Sib), que continúa con la relación cromática de los sonidos anteriores del cluster. El Sib está duplicado en cinco octavas: el cambio de textura marca el comienzo de la Sección II (ver Figura 2), iniciándose un nuevo proceso de construcción de un cluster, que culmina en el compás 54 (Tabla 4). Este nuevo cluster no lo es en un sentido estricto ya que los sonidos que lo integran están distribuidos en diferentes octavas. Se trata, en rigor, de un agregado de nombres de notas contiguas. ${ }^{9}$

\footnotetext{
${ }^{9}$ Hemos omitido intencionalmente el uso de la codificación implementada por Allen Forte, que resultaría innecesariamente engorrosa en este contexto.
} 
Tabla 4 Esquema de la formación del pseudo-cluster en la Sección II

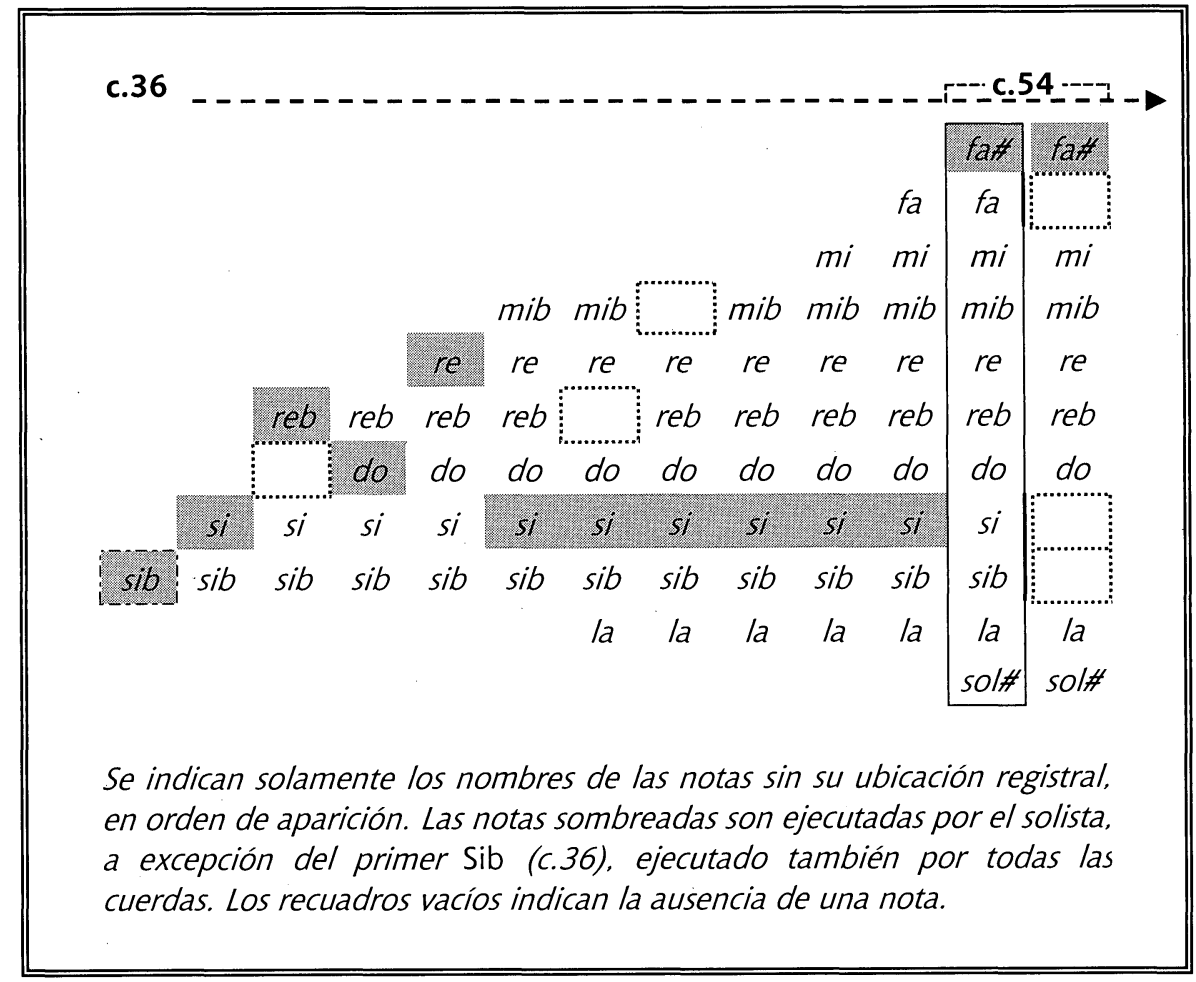

A diferencia del primer cluster, el nuevo pseudo-cluster disloca el fenómeno de la contigüidad de las alturas por medio de la distribución en diferentes octavas. El intervalo de octava - como ya vimos - es el que define el importante punto de articulación formal del compás 36, con la duplicación del Sib. Se podría argumentar que la conservación del nombre de las notas en el pseudo-clusteraún modificándose el contenido interválico - traslada la organicidad otorgada por la contigüidad de las alturas a una organicidad más abstracta que reside en la contigüidad de los nombres de las notas. Al hacerlo, Ligeti establece una continuidad entre el objeto y su nombre.

En este punto del análisis cabe hablar de un principio de expansión o derivación que opera en forma de desvíos mínimos de un material inicial: el unísono. Consideramos al unísono como punto de partida para llegar al clustery. a su vez, como núcleo de la duplicación de octavas ya mencionada, que da lugar 
al proceso de armado del pseudo-cluster. Si entendemos a la duplicación de octavas como un desvío del unísono - en tanto es la primera relación armónica ya contenida en la fundamental -, la expansión cromática del cluster también aparece como un desvío a partir de una aglomeración inicial, cuyos agregados posteriores se incorporan por semitono, es decir, por el escalón o intervalo más pequeño dentro del sistema temperado. En el primer caso, la relación de parentesco es cercana por razones acústicas; en el segundo; el parentesco cercano se da por contigüidad espacial en una sucesión ordenada y preexistente de nombres de notas adyacentes - la escala cromática -, dentro o fuera de la octava.

La identidad de los materiales se mantiene en el tiempo por medio de mínimas diferencias que enfatizan el carácter estático del Primer Movimiento. Los cambios importantes, como la aparición de notas nuevas o las modificaciones en la textura, están precedidos por pequeñas señales anticipatorias que vinculan zonas más o menos estables por medio de refinados procedimientos de instrumentación/variación. Tres claros ejemplos son:

- La entrada de la nota nueva Fa (c. 17), formando parte del trino Mi-Fa del clarinete, está anticipada por un doble proceso de ampliación:

1. En el compás 13 se presenta un "ensanchamiento" de la afinación del $M i$, por el agregado de dos notas desviadas del sistema temperado (Figura 3a). Se trata de un proceso de analogía, en una escala reducida a su mínima expresión acúștica, del procedimiento acumulativo por adición de escalones contiguos que aparece en la Sección I.

2. En los compases 14-16 la anticipación se produce con un trémolo sobre el Mi en las cuerdas y por un cambio de color y posterior trémolo del solista, también sobre la nota Mi. Esta doble vinculación asocia el trémolo de las cuerdas con el trino 
del clarinete y al trémolo en sí mismo, repartido entre las cuerdas y el solista (Figura 3b).

- La formación del cluster en el compás 26 - que en el compás 28 alcanza su amplitud máxima (5ta. justa) - está anticipada por una mayor densidad instrumental en las notas Mi-Fa, únicas usadas hasta ese momento, acompañadas por un crescendo ( $p p p p$ a $m p$ ) en los compases 25-26 (Figura 3c). Se trata de un procedimiento que equipara, indirectamente, la mayor densidad instrumental con una mayor cantidad de alturas en el cluster.

- La irrupción del Si b (c. 36) - punto de inflexión entre las Secciones I y 1 - está precedida por un gradual relevo tímbrico, que culmina en el compás 33 con el reemplazo de las cuerdas por los vientos en las notas del cluster. ${ }^{10}$ El Si $b$ también está precedido por una desintegración del cluster, suprimiéndose alternadamente algunos de sus sonidos, como se describió más arriba (ver Tablas 3 y 5). Es importante señalar en este contexto, como principio de economía y variación, la eliminación de las cuerdas, originando una suerte de vacío tímbrico (cc. 34-35) que jerarquiza más adelante la reaparición de esos instrumentos en la duplicación del Sib (c. 36).

${ }^{10}$ A excepción del Sol, tocado por la viola hasta el final del compás 33. Este sonido es el último que desaparece, sin ser reemplazado. 


\section{afinación del Mi (c.13) \\ c. 13 \\ F1.

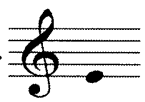

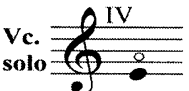 \\ Cb. $\frac{0^{111}}{\sqrt[3]{0}}$ \\ Sonido de afinación temperada. \\ Armónico natural de tercera. Afinación baja (-14 cents) con respecto al sistema temperado.* \\ Armónico natural de quinta. Afinación alta (+2 cents) con respecto al sistema temperado.*}

Figura 3a Anticipación de la entrada del Fa (c.17) por "ensanchamiento" en là

Ligeti pide en la partitura no corregir la diferencia de afinación entre los armónicos naturales para que se produzcan oscilaciones de frecuencia entre los sonidos (batidos).

Figura 3b Anticipación tímbrica de la entrada de/ Fa (c.17)

Trémolo de cuerdas

(cc.14-16)

\section{Solista}

(cc.16-17)
Trino de clarinete

(c. 17 y sig.)
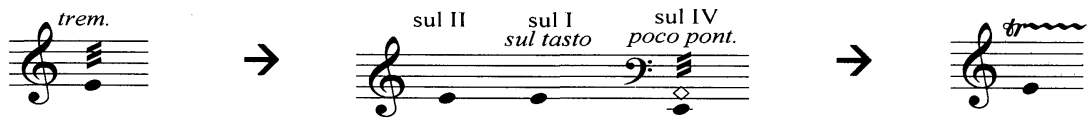

Figura 3c Anticipación de la formación del cluster de la Sección I

Mayor densidad y crescendo (cc.25-26)

cluster (c.26)

trompeta

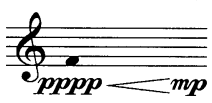

violín I

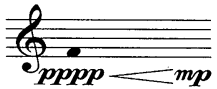

violín //

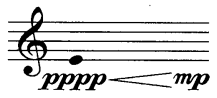

viola
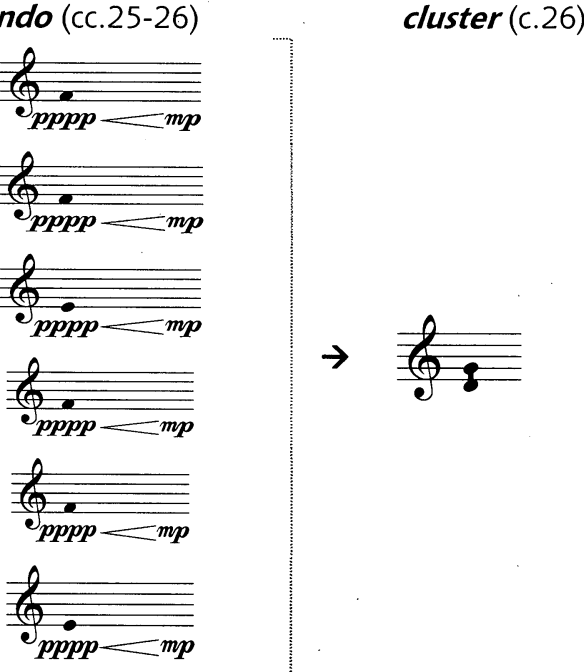

violonchelo

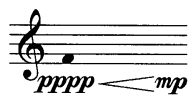

contrabajo

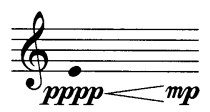

Figura 3 Procedimientos de anticipación 
Tabla 5 Esquema de reemplazo tímbrico y desintegración del cluster de la Sección I

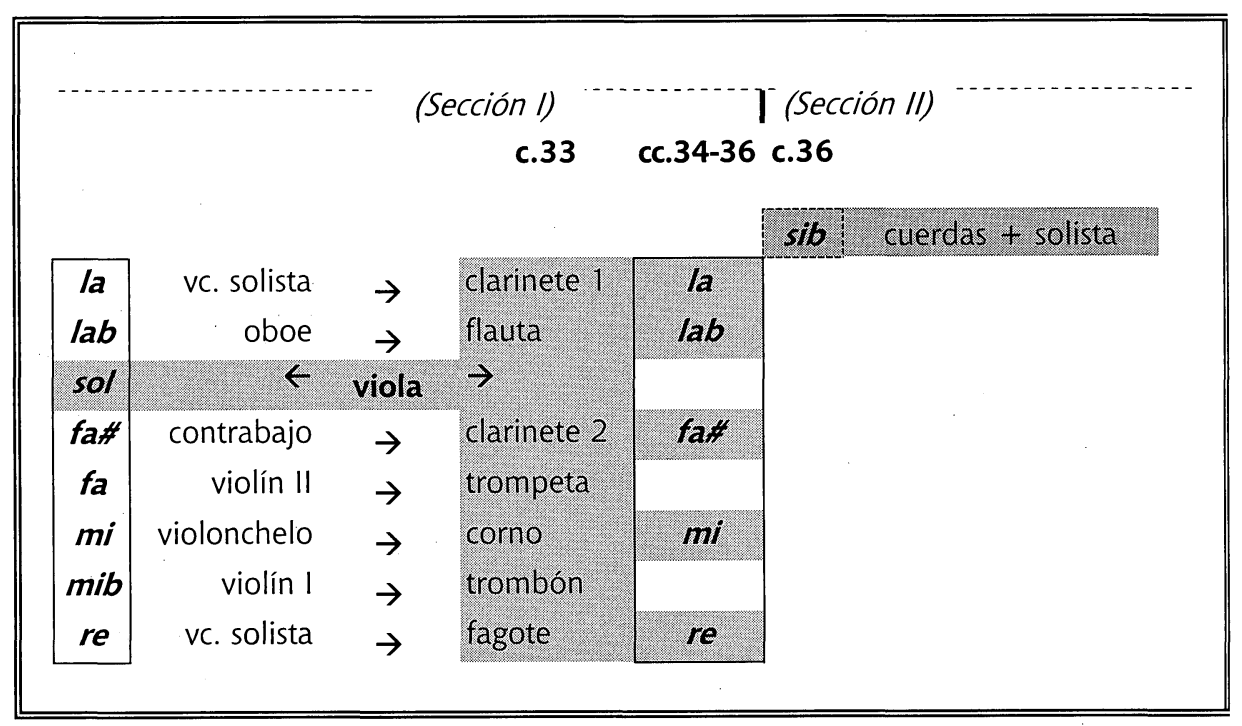

En este Movimiento - que carece de los giros convencionales y de la separación del individuo y la masa propios del concierto- surge en el solista, 20 apenas insinuado, el gesto melódico. Parodia y residuo, este gesto consiste en tres evocaciones por grado conjunto con la indicación molto expresivo, cuyas manifestaciones extremas son simétricas: al ascenso del gesto melódico de la Sección I corresponde el descenso del segundo gesto melódico de la Sección II (Figura 4).

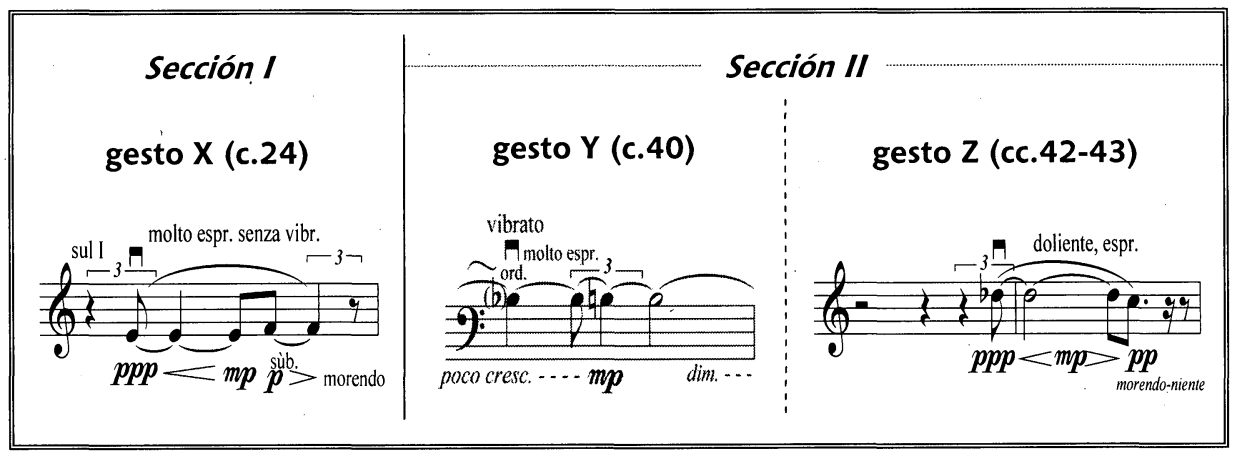

Figura 4 Gestos melódicos del solista (Secciones I y II) 
Esta simetría se halla reforzada por el marco de silencios que rodean a ambos gestos en contraposición al gesto melódico central (c. 40).

Recordemos que a partir de la Sección II comienzan a agregarse notas, en orden sucesivo y ascendente, integrando gradualmente el pseudo-cluster que culmina en el compás 54 (ver Tabla 4). En este proceso, llevado a cabo por el solista hasta la nota $R e$ y luego continuado por la orquesta (como se observa en la Tabla 4), se omite transitoriamente el Do, antes de la aparición del Reb. El compositor omite el Do para permitir el descenso del gesto melódico Reb-Do sin repetir las notas utilizadas hasta ese momento (Tabla 6). Este procedimiento de no repetición tal vez constituya una fugaz aparición de una de las premisas del pensamiento dodecafónico, fuera de contexto.

Tabla 6 Modificación del orden de aparición de las notas del solista

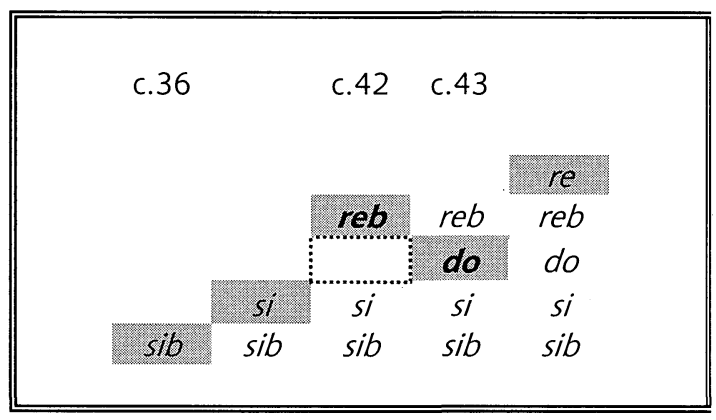

Los gestos melódicos remiten a la esencia cromática del cluster, no solamente por su contenido interválico de semitonos sino porque Mi-Fa (gesto X) son los sonidos 1 y 2 del primer cluster, mientras que Reb-Do (gesto Z) son los sonidos 3 y 4 del pseudo-cluster. el carácter complementario de la simetría ascendente-descendente de los gestos melódicos $X$ y $Z$ se ve reforzado por otra complementación que integra a los dos clusters en una continuidad (sonidos 1, 2, 3 y 4). Por otro lado, entre los gestos $Y$ y $Z$ también se verifica una complementación ya que los sonidos que los integran son los 4 primeros del pseudo-cluster (Sib-Si-Do-Reb). Se produce así una doble 
complementación: contigua entre los gestos $Y$ y $Z$ y otra a distancia entre los gestos extremos $X$ y $Z$ (Tabla 7$)$.

Tabla 7 Complementación entre los gestos melódicos del solista

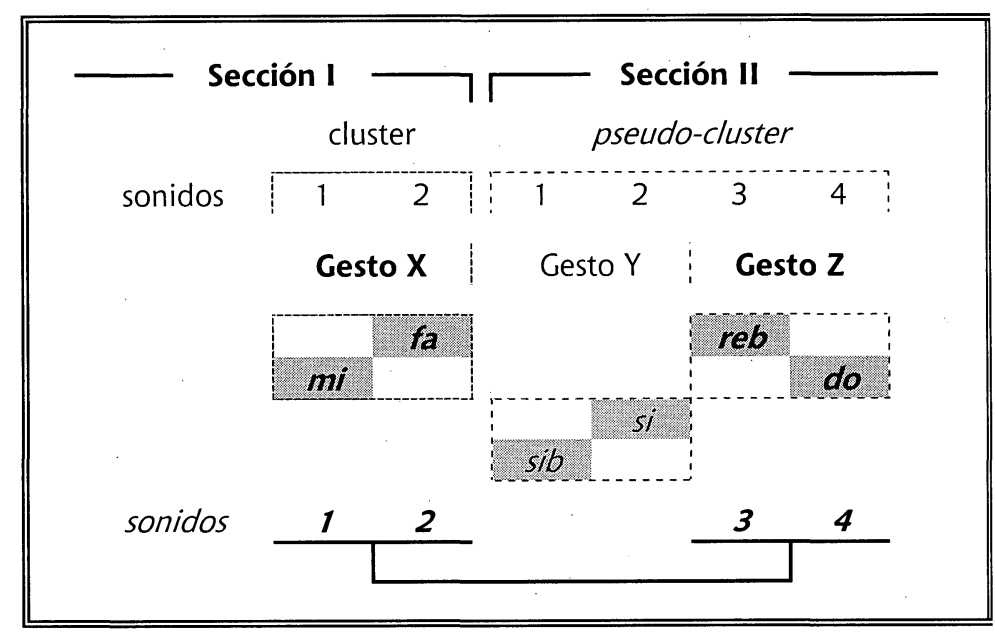

La sugerencia de la imposibilidad de lo melódico proviene del extremo ascetismo de sus magras apariciones y de la dependencia constructiva respecto a lo armónico, el cluster. Por otro lado, se comprueba

22 una relación complementaria que vincula a los gestos melódicos extremos $x$ y $Z$ en la distribución de las duraciones de la macroforma. Cada uno de esos gestos es casi equidistante de un punto de articulación formal importante: el gesto $X$ aparece en $\boldsymbol{a}^{\prime}$ habiendo transcurrido 25 negras más 1 corchea de tresillo ( $=25,33$ negras) desde el punto de articulación intermedio de la Sección I; el gesto $Z$ lo hace en $\boldsymbol{b}$ después de 25 negras más 1 negra de tresillo (= 25,66 negras) del punto de articulación entre las Secciones I y II (Tabla 8). 
Tabla 8 Quasi simetría en la aparición de los gestos melódicos extremos del solista

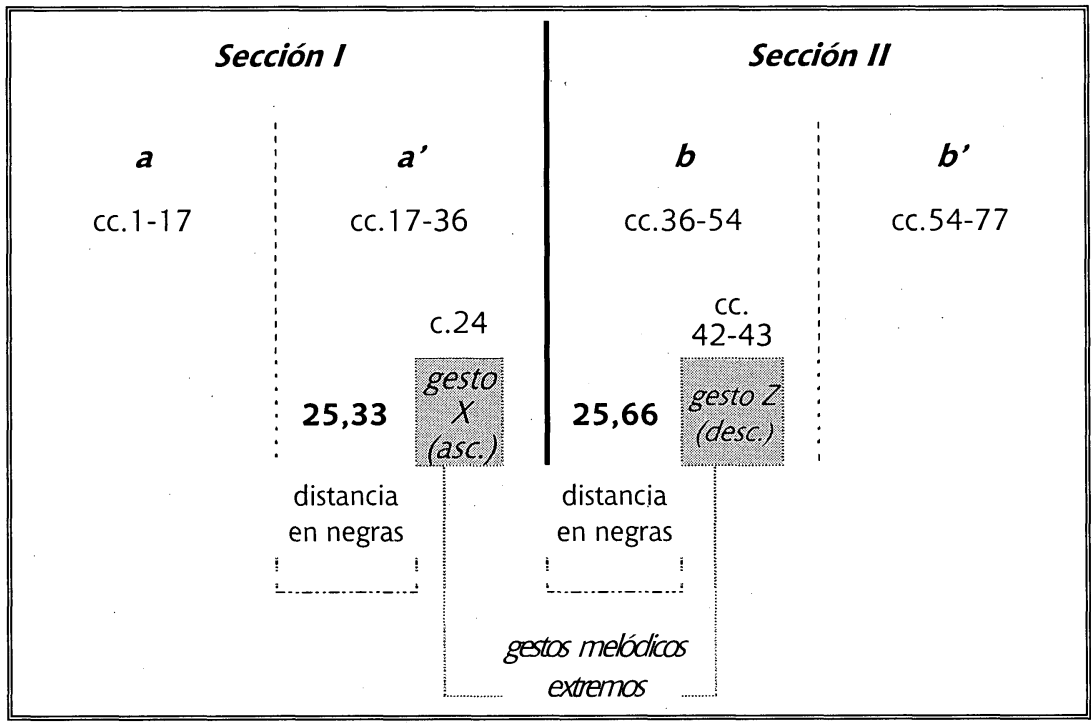

La forma es una transposición espacial de un fenómeno temporal, dice Ligeti (1970). Así acontece cuando el compositor piensa la obra como totalidad, articulada o no en secciones más o menos diferenciadas, previamente a su terminación. Aplicando esa hipótesis a este Primer Movimiento, la macroforma presenta una peculiaridad en las simetrías de las duraciones de los segmentos; la simetría también se observa en la correspondencia entre sonido y silencio.

Para comenzar a explicar la primera simetría, debe señalarse ante todo la singular utilización del silencio, que aparece únicamente en el final. Son seis compases de silencio absoluto (cc. 72-77) que Ligeti pide expresamente que no sean marcados por el director, quien debe reiniciar la marcación con el Segundo Movimiento. ${ }^{11}$ Estos seis compases cumplen dos funciones: por un lado

11 El compás 71 es ambiguo, perteneciendo todavía a los compases sonoros, a pesar de tener un silencio escrito: el silencio está entre paréntesis, hay una ligadura que indica que el sonido precedente se extingue en algún momento indefinido y la indicación morendo al niente se extiende aún sobre ese compás. Por otro lado, la indicación de no marcar los silencios rige a partir del compás 72. Así queda clara la intención de que únicamente los últimos seis compases sean considerados de silencio absoluto. 
constituyen una separación rigurosamente medida entre ambos Movimientos; por el outro - en su función más importante - equiparan la duración del comienzo y el final del Primer Movimiento. En efecto, los seis compases finales de silencio se corresponden, en la duración, con los seis compases iniciales ejecutados por el solista. Esta simetría de opuestos, sonido/silencio, se lleva a cabo en la variable duración, única vinculación entre sonido y silencio, recordando el conocido e insoslayable pensamiento de John Cage (Tabla 9).

Tabla 9 Relación simétrica entre el sonido inicial y el silencio final

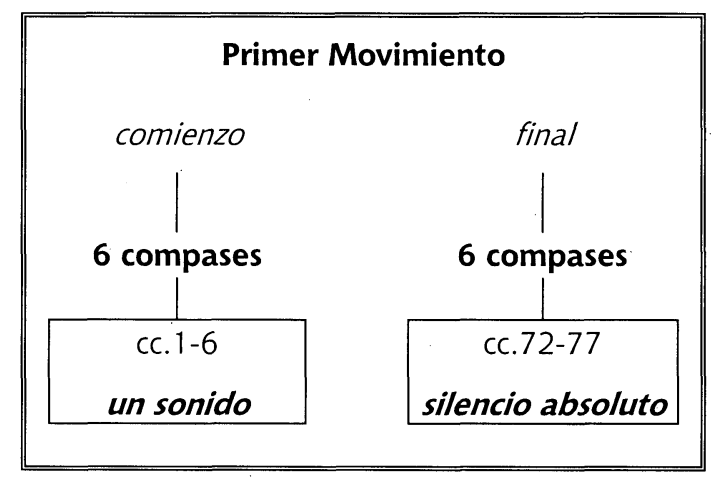

Una nueva simetría se constata entre el comienzo y el final en el modo de ejecución y extinción del sonido: en el comienzo se le pide al solista un "ataque imperceptible, como viniendo de la nada y apareciendo gradualmente por medio de un crescendo apenas perceptible»; al final del movimiento, el último sonido, ejecutado por el contrabajo, se extingue poco a poco, "morendo al niente". Asimismo, los últimos seis compases de silencio enmascaran una división simétrica y binaria de la macroforma: si omitimos esos seis compases de silencio absoluto, reteniendo para el análisis solamente los 71 compases de sonido sin interrupción alguna, observamos claramente una división binaria. Cada sección tiene una duración exacta de 35 compases y medio, separados por la entrada del Sib del compás 36, ya descripta (Ver Tabla 10). 
La sutileza que Ligeti muestra en la construcción de la forma reside en el enmascaramiento de una relación simétrica simple, por medio de la utilización de otra relación simétrica que le otorga al silencio una importancia estructural.

Tabla 10 Relaciones simétricas en el Primer Movimiento

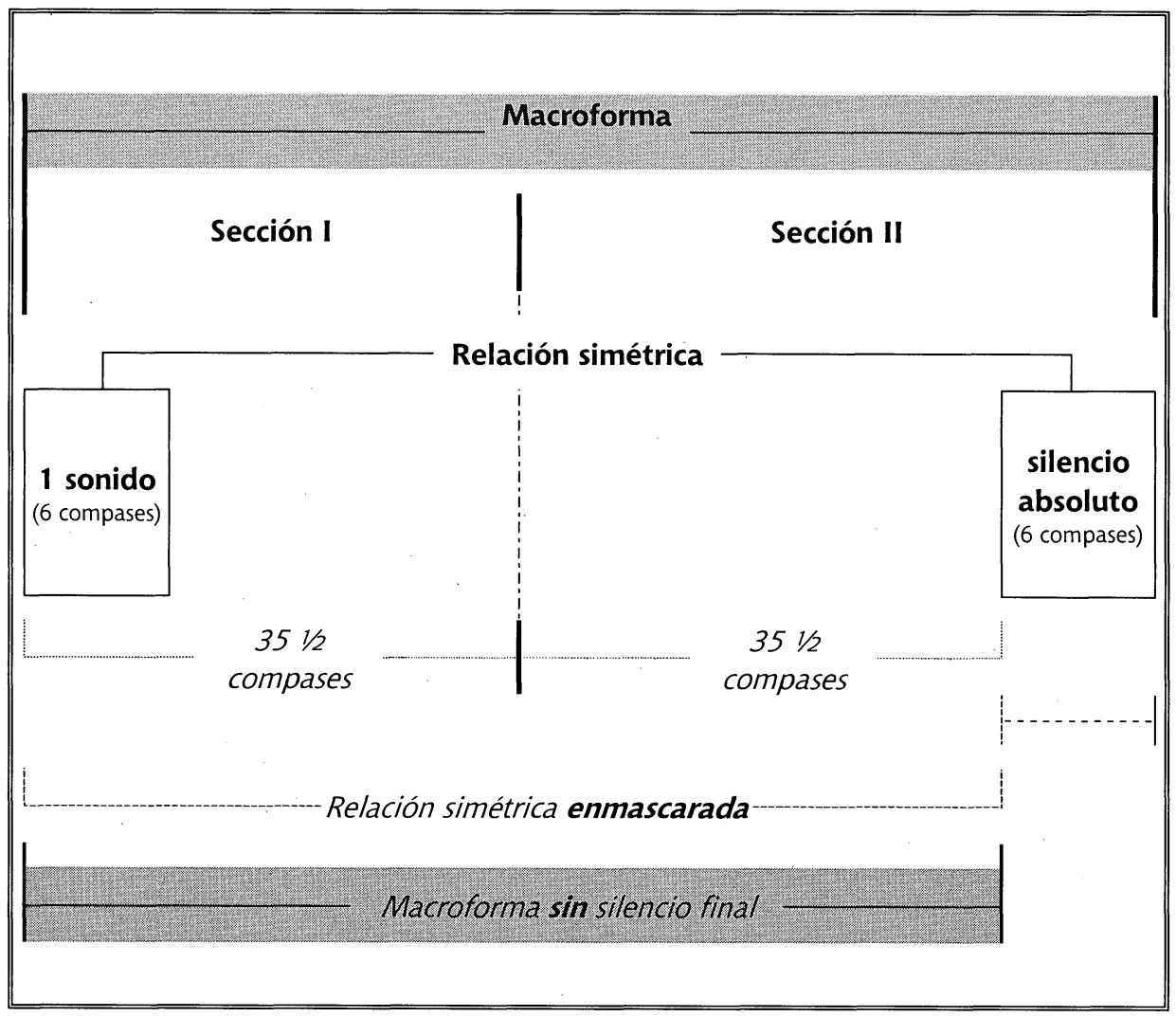

En este Movimiento el trabajo con franjas registrales selectivas se amplía con la utilización de indicaciones en forma de breves leyendas que refinan las habituales indicaciones de carácter. La idea de desintegración - evidente en la textura y en la misma relación no convencional entre el solista y la orquesta - se manifiesta en las zonas finales de ambos Movimientos: en el Primero el solista concluye su participación en el límite del registro agudo y en el Segundo mediante la transición del sonido al ruido. Un Concierto que casi no es un Concierto, que comienza desde la nada y se disuelve en la nada, esta obra de 
Ligeti parece ubicarse en los límites de la disgregación. La disgregación afecta no sólo a uno de los géneros arquetípicos del romanticismo sino que se expande hacia el borde de los límites perceptivos de la intensidad sonora y de la identificación de los timbres. También el concepto de melodía se presenta apenas insinuado, junto a un manejo definidamente espacial de contracción y expansión del registro, sostenido siempre por una orquestación que promueve la generación de timbres complejos.

\section{Referencias}

BARTHES, Roland. El "grano" de la voz. En: Lo obvio y lo obtuso. Barcelona, España: Paidós, 1986. p. 262-271.

HÄUSLER, Joseph. D’Atmosphères a Lontano, un entretien entre György Ligeti et Joseph Häusler. Musique en jeu, Editions du Seuil, Paris, n. 15, p. 119, Setiembre 1974.

LIGETI, György. Ich will eine schmutzige Musik, eine irisierende Musik... Entrevista de Maria Lobanova. Neue Zeitschrift für Musik (NMZ), Mainz, Alemania, n. 3. p. 17, mayojunio 2003. Versión castellana: Quiero una música "súcia", una música iridiscente.... Arte y Opinión, n. 2. Trad. María Cecilia Villanueva y Mariano Etkin. Facultad de Bellas Artes, Universidad Nacional de La Plata, Argentina, p. 29, 2006. (Colección Breviarios).

. De la forme musicale. $V H$ 1.01, Paris, n. 1, p.77-88, Primavera 1970.

26 SCHNEBEL, Dieter. Composition 1960: La Monte Young (1971). Musique en jeu, Editions du Seuil, Paris, n. 11, p. 7-16, junio 1973.

WAGNER, Richard. Parsifal. 1er. Acto. Libreto. París, Francia: Éditions Montaigne, 1944. p. 98.

XENAKIS, Iannis. La crise de la musique serielle. Gravesaner Blätter, Gravesano, Suiza, n. 1. p. 2-4,1955.

\footnotetext{
Mariano Etkin: marianoetkin@hotmail.com María Cecilia Villanueva: mceciliavillanue@hotmail.com

Artigo recebido e aprovado em 09 de junho de 2009
} 